\title{
Endokrin Bozucular
}

\section{Endokrin Bozucular}

\author{
Ayşegül Aksan ${ }^{1}$, Aslıhan Özdemir ${ }^{1}$ \\ ${ }^{1}$ Hacettepe Üniversitesi Sağlık Bilimleri Fakültesi Beslenme ve Diyetetik Bölümü, Ankara, Türkiye
}

\section{Özet}

Endokrin bozucular; endokrin sistem fonksiyonlarını etkileyerek organizmada ve organizmanın nesillerinde olumsuz sağlık etkileri oluşturan ekzojen madde veya madde karışımlarıdır. Bu maddeler doğal hormonların sentez, sekresyon, taşınma, metabolizma, bağlanma reaksiyonları, aktiviteleri, vücuttan atılımları ve hatta hedef hücredeki etkilerini değiş̧irebilmektedirler. Endokrin bozucular; etkilerini sıklıkla steroid hormonlar ya da peptid/protein yapıda hormonlar üzerinden gösterirler. Yaşamın erken dönemlerinde endokrin bozuculara maruz kalınması sonucu oluşan gen metilasyonlarının yaşamın ileri dönemlerinde ortaya çıkan hastalıkların temelini oluşturduğu ve bu genetik değişimin nesilden nesile aktarılabildiği düşünülmektedir. Bu derleme yazıda endokrin bozucuların tanımı, sınıflaması, fizyolojik etkileri ile ilgili bilgi verilmekte; üreme sağlı̆ı, tiroid fonksiyonları, obezite, diabetes mellitus, metabolik sendrom ve beslenme ile ilişkisi tartışılmaktadır.

Anahtar kelimeler: Endokrin Bozucular, Metabolik Bozucular, Obezite, Beslenme

Sorumlu Yazar: Ayşegül Aksan, Hacettepe Üniversitesi, Sağlık Bilimleri Fakültesi, Beslenme ve Diyetetik Bölümü, Ankara, Türkiye, aysegul.cakmak@hacettepe.edu.tr 


\title{
Endocrine Disruptors
}

\section{Endocrine Disruptors}

\author{
Ayşegül Aksan ${ }^{1}$, Aslıhan Özdemir ${ }^{1}$ \\ ${ }^{1}$ Hacettepe University Sağl1k Faculty of Health Sciences Department of Nutrition and Dietetics, \\ Ankara, Turkey
}

\begin{abstract}
Endocrine disruptors are exogenous substances or mixtures that alter function(s) of the endocrine system and consequently cause adverse health effects in an intact organism, or its progeny, or (sub)populations. These substances may alter the production, release, transport, metabolism, binding, action, elimination and even their effects on target cells. Endocrine disruptors usually present their functions through steroidal or peptide/protein hormones. Gene metilations as a result of exposure endocrine disruptors in early stages life cause the basis of developing adult diseases and these genetic changes pass down from generation to generation. In this review; definition, classification, physiologic actions of endocrine disruptors are revealed with information on health, and also the interaction relation between endocrine disruptors and reproductive health, thyroid functions, obesity, diabetes mellitus, metabolic syndrome and nutrition as are discussed.
\end{abstract}

Keywords: Endocrine Disruptors, Metabolic Disruptors, Obesity, Nutrition

Corresponding Author: Ayşegül Aksan, Hacettepe Üniversitesi, Sağlık Bilimleri Fakültesi, Beslenme ve Diyetetik Bölümü, Ankara, Türkiye, aysegul.cakmak@hacettepe.edu.tr 


\section{Giriş}

Endokrin bozucular; endokrin sistem fonksiyonlarını etkileyerek organizmada ve organizmanın nesillerinde olumsuz sağlık etkileri oluşturan ekzojen madde veya madde karışımlarıdır (Andreas Kortenkamp, Faust, Evans, McKinlay, Orton ve Rosivatz, 2011, Solecki, Kortenkamp, Bergman, Chahoud, Degen, Dietrich ve diğ., 2016). Bu maddeler doğal hormonların sentez, sekresyon, taşınma, metabolizma, bağlanma reaksiyonları, aktiviteleri, vücuttan atılımları ve hatta hedef hücredeki etkilerini değiştirebilmektedirler (Palioura, Kandaraki ve Diamanti-Kandarakis, 2011) ve bu etkilerin birkaçı bir arada olabilmektedir. Klinikte ortaya çıkan bulgular, tüm etkilerin bir arada bulunmasıyla görülmektedir (Teilmann, Juul, Skakkebæk ve Toppari, 2002).

Endokrin bozucular insan, hayvan ve bitki kaynaklı (fitoöstrojenler) olabildikleri gibi, sentetik ve endüstriyel kimyasal kaynaklı da olabilmektedirler (Casals-Casas ve Desvergne, 2011). Herhangi bir maddenin endokrin bozucu olarak tanımlanabilmesi için sağlık üzerine olumsuz etkisinin olması ve bu etkiyi endokrin sistem üzerinden gerçekleştirmesi gerekmektedir (Andreas Kortenkamp ve diğ., 2011; Palioura ve diğ., 2011). Endokrin bozucuların etkileri endokrin sistem ile kontrol edilen herhangi bir fizyolojik süreçte gözlenebilir ve endokrin bozucuların etkili olmadığı bir fizyolojik sürecin mümkün olmadığı düşünülmektedir. Endokrin bozucular doğrudan etkili olamadıkları organ ve sistemleri de dolaylı olarak etkileyebilmektedir (Casals-Casas ve Desvergne, 2011).

\section{Sinıflama}

Endokrin bozucu etkiye sahip bileşikler 3 grupta incelenebilir (Keith, 1998);

1. Sentetik olarak üretilen hormonlar: $\mathrm{Bu}$ grupta doğum kontrol ilaçları, hormon replasman tedavileri ve bazı hayvansal gida katkı maddeleri yer almaktadır (Çetinkaya, 2009).

2. Doğal endokrin bozucular: Bu grup endokrin bozucular sıklıkla fito-östrojenler olarak adlandırılırlar, soya fasulyesi, elma, kiraz gibi besinlerde doğal olarak bulunurlar (Keith, 1998). Doğal hormon yapısında olduklarından düşük dozlarda kolayca yıkılır ve depolanmazlar (Çetinkaya, 2009).

3. Çevresel endokrin bozucular: Bu maddeler genel olarak endüstri alanında kullanılmak üzere geliştirilmiş kimyasallar ve farklı çevresel kirleticilerdir (Keith, 1998; Çetinkaya, 2009). Bu grupta; biyosidler, insektisitler, herbisitler, nematositler, fungusitler, endüstriyel kimyasallar (bisfenol A, polivinil karbon), ağır metaller, 
poliklorin bifeniller ve ticari kullanım amacı olmayan, diğer kimyasalların parçalanmaları ile ortaya çıkabilen çevresel kirleticiler yer almaktadır (Keith, 1998).

\section{Fizyolojik Etkiler}

Birçok endokrin bozucu lipid (steroid hormonlar) veya aminoasit türevi hormonlar (tiroid hormonlar) ile etkileşimde olup, protein/peptid yapıda hormonların sentez ve uyarılarını da etkileyebilirler. Endokrin bozucular; etkilerini sıklıkla steroid hormonlar ya da peptid/protein yapıda hormonlar üzerinden gösterirler (Andreas Kortenkamp ve diğg., 2011; Jenkins, Raghuraman, Eltoum, Carpenter ve Russo, 2009; Moral, Wang, Russo, Mailo, Lamartiniere, Russo, 2007). İtalya'da yapılan bir çalışmada, kırsal alandaki hava kirliliğine maruz kaldığı düşünülen kadın trafik polislerinin foliküler ve luteal fazlarında östrojenik bir hormon olan 17- $\beta$-östradiolün plazma düzeylerinin kontrol grubundaki kişilere göre daha düşük olduğu bulunmuştur (Tomei, Ciarroca, Fortunato, Capozzella, Rosati, Cerratti, ve diğ., 2006).

Endokrin bozucuların bir diğer mekanizması da genler üzerinde doğrudan etki göstermesidir. Örneğin östrojenik etki gösteren endokrin bozucuların DNA hasarına ve dolayısıyla etkilediği hücre ve hücre gruplarında malignant farklılaşmalara neden olduğu belirlenmiştir (Bolton ve Thatcher, 2007). Östrojen benzeri endokrin bozucuların meme kanseri ile ilişkisinin araştırıldığg bir çalışmada, poliklorinli bifenillerin bir türünün (PCB138) 20 yaş üstü kadınlarda meme kanseri ile belirgin olarak ilişkili olduğu bulunmuştur (Morgan, Deoraj, Quentin ve Deodutta, 2016).

Son yıllarda endokrin bozucuların epigenetik etkileri de tartışılmaktadır. Yaşamın erken dönemlerinde endokrin bozuculara maruz kalınması sonucu oluşan gen metilasyonlarının yaşamın ileri dönemlerinde ortaya çıkan hastalıkların temelini oluşturduğu (Skinner, 2011) ve bu genetik değişimin nesilden nesile aktarılabildiği düşünülmektedir (Anway ve Skinner, 2008, Walker ve Gore, 2016).

\section{Endokrin bozucuların organizmaya etkisini değiştirebilen etmenler}

Maruz kalma yaşı: Gelişmekte olan bir organizma ile (bebek ya da fetus) yetişkin bir bireyin endokrin bozucu ajanlara maruz kalmasının farklı sonuçlar ortaya çıkarabileceği düşünülmektedir. Endokrin bozucuların etkisini araştıran birçok çalışma alanında fetal dönem etkilerini tanımlayabilmek için "yetişkin hastalıklarının fetal temelleri” (Barker, 2004), yaşamın her dönemindeki maruziyetin farklı etkilerini açıklayabilmek için de "yetişkin hastalıkların gelişimsel temelleri” (Diamanti-Kandararkis, Bourguognin, Giudice, Hauser, 
Prins, Soto ve diğ., 2009) tanımlamaları kullanılmaktadır. Endokrin bozuculara erken maruziyetin etkilerinin geri dönüşsüz olabileceği düşünülmektedir (Barker, 2004).

Maruziyet sonrası geçen süre: Endokrin bozuculara maruziyetin sonuçları hemen gözlenmeyebilir, kronik maruziyet ya da organizmanın gelişimi endokrin bozucuların etkilerinin gözlenmesine neden olabilir (Diamanti-Kandarakis ve diğ., 2009).

Karışım (kokteyl) etki: Farklı endokrin bozucular birbirlerinin etkilerini arttırabildikleri gibi birlikte daha farklı etkilerin gözlenmesine de neden olabilir, sinerjist etki gösterebilirler (Kortenkamp, 2007).

Alışılmamış doz-yanıt dinamiği: Endokrin bozucuların doz-yanıt mekanizmaları ile ilgili farklı görüşler bulunmaktadır. Bunlardan ilki; endokrin bozucuların en düşük dozlar dahil olmak üzere her dozda etkili olabildiği yönündedir. Bu görüşe göre önemli olan, endokrin bozuculara kritik pencere olarak adlandırılan gelişimsel dönemdeki maruziyettir (Diamanti-Kandarakis ve diğ., 2009). Bir diğer görüş de endokrin bozucuların düşük ve yüksek dozlarda daha etkin olduğudur. $\mathrm{Bu}$ görüşe göre endokrin bozucuların etkileri $\mathrm{U}$ şeklinde grafik ile gösterilebilir (Diamanti-Kandarakis ve diğ., 2009; vom Saal, Akingbemi, Belcher,Birnbaum, Crain, Eriksen ve diğ., 2007).

Epigenetik etki, genetik aktarım: Endokrin bozucuların etkileri yalnızca maruz kalan birey ya da nesilde değil daha sonraki nesillerde de gözlenebilir. Bu aktarım yalnızca fetusun/yumurtanın etkilenmesi (Anway, Cupp, Uzumcu ve Skinner, 2005) ile değil, DNA mutasyonu, metilasyonu ya da histon asetilasyonu ile de gerçekleşebilir (Anway ve Skinner, 2008; Anway, Cupp, Uzumcu ve Skinner, 2005; Gluckman ve Hanson, 2004)

\section{Üreme Sağlığı ve Endokrin Bozucular}

Endokrin bozucuların üreme sağlığı üzerine etkileri yapılan çalışmalarla en iyi aydınlatılmış etkilerindendir. Yapılan çalışmalarda endokrin bozucuların kadınlarda puberteden menapoza kadar kadın yaşamının birçok döneminde farklı etki mekanizmasına ve patogeneze sahip olduğunu göstermektedir (Diamanti-Kandarakis, Palioura, Kandarakis ve Koutsilieris, 2010; Woodruff, Carlson, Schwartz ve Giudice, 2008). Endokrin bozucular kadınlarda erken/geç puberteye, polikistik over sendromuna, doğurganlığın azalmasına, kısırlığa, endometriozise, erken over yetmezliğine, rahim tümörlerine, anöploidiye, gebelik komplikasyonlarına, meme tümörleri ve endometriyal tümörlere neden olabilmektedir (Diamanti-Kandarakis ve diğ., 2009; Caserta, Maranghi, Mantovani, Marci, Maranghi ve Moscarani, 2008). Yapılan bir çalışmada, kadınlarda herbisit ve fungisit gibi endokrin bozuculara maruziyet ile üreme sağlığı problemleri arasında ilişki olduğu bulunmuştur 
(Greenlee, Arbuckle ve Chyou, 2003). Erkek üreme sistemlerinde ise endokrin bozucuların etkileri ile ilgili çalışmalar sperm kalitesinde düşüşe, kısırlığa, ürogenital abnormalitelere ( hipospadias, kriptorşidizm) ve testiküler germ hücreli tümörlere neden olabildiğini göstermektedir (Sharpe ve Skakkabaek, 2003; Skakkebaek, Rajpert-De Meyts ve Main, 2001). Fitalat ve bisfenol A gibi hızlı metabolize edilen bileşenler ve organik kirleticiler ile erkek üreme sağlı̆̆ bozuklukları arasındaki ilişkinin incelendiği bir sistematik derlemede, maruziyetin artışının hastalık riskini arttırdığı bulunmuştur (Bonde, Flachs, Rimborg, Glazer, Giwercman, Ramlau-Hansen ve diğ., 2016).

\section{Tiroid Fonksiyonları ve Endokrin Bozucular}

Tiroid hormonları organizmanın düzenleyici olup, normal fizyolojik sürecin sürdürülmesinde büyük öneme sahiptirler (Heyland ve Moroz, 2005). Endokrin bozucuların tirotropin düzeyini, tiroid volümünü, tiroid antikor düzeyini etkilediği yönünde çalışmalar bulunmaktadır (Howdeshell, 2002; Boas, Feldt-Rasmussen, Skakkabaek ve Main, 2006; Zoeller, 2007).

Endokrin bozucular ve tiroid hormon etkileşiminin en çok fetal dönemde büyüme ve beyin gelişiminde önemli olduğu düşünülmektedir (Boas, Feldt-Rasmussen, Skakkebaek ve Main, 2006). Dirençli organik kirleticilere prenatal maruziyet ile tiroid düzeyleri arasındaki ilişkiyi incelemek amacıyla yapılan bir çalışmada, yenidoğan bebeklerin kord ve maternal serumlarındaki poliklorlu bifenil, polibromin difenil eter ve organoklorlu pestisit düzeyleri ve tiroid hormonlarının konsantrasyonları incelenmiştir. $\mathrm{Bu}$ organik kirleticilerin düzeyleri ile tiroid hormon konsantrasyonları arasında ters ilişki saptanmıştır (Kim, Park, Kim, Lee, Choi, Choi ve diğ., 2015)

\section{Obezite, Diabetes Mellitus, Metabolik Sendrom ve Endokrin Bozucular}

Obezite endokrin ilişskili bir hastalık olduğundan endokrin sistem üzerine etki eden endokrin bozuculara duyarlıdır (Mauvais-Jarvis, Clegg ve Hevener, 2013; Sargis, Johnson, Choudry ve Brady, 2010). Her ne kadar obezitenin temel nedeni yüksek enerji alımına karşılık düşük fiziksel aktivite düzeyi olarak gösterilse de son yıllardaki obezite epidemisinin oluşumunda endokrin bozuculara maruziyetin de etkili olduğu düşünülmektedir (Newbold, Padilla-Banks, Jefferson ve Heindell, 2008; Newbold, 2010; Keith, Redden, Katzmarzyk, Boggiano, Hanlon, Benca ve diğ., 2006).

Yapılan hayvan çalışmalarında tributlin, bisfenol A, organoklorin ve organofosfat pestisitleri, hava kirliliği, kurşun, dietilstilbestrol, perflorooktanoik asit, monosodyum 
glutamat ve nikotin maruziyetinin yaşamın ileri dönemlerinde vücut ağırlığında ve kolesterol düzeyinde artışa neden olduğu gösterilmiştir (Newbold, Padilla-Banks, Jefferson ve Heindel, 2008; Dirinck, Jorens, Covaci, Geens, Roosens, Neels ve diğ., 2011; Janesick ve Blumberg, 2011).

İnsanlarda yapılan az sayıda çalışma ise endokrin bozuculara maruziyetin yağ hücresi sayısında artışa, beyindeki iştah merkezini etkileyerek besin alımı ve besin ögesi metabolizmasında değişime, beyin, pankreas, adipoz doku, karaciğer, kas, gastrointestinal sistem gibi endokrin ve endokrin aracılı organlar yoluyla lipid metabolizması ve insülin duyarlılığında farklılaşmaya neden olduğu ve bu şekilde obezite oluşumuna yol açabildiğine işaret etmektedir (Tang-Peronard, Andersen, Jensen ve Heitmann, 2011).

Bazı endokrin bozucular pankreasın beta hücrelerini etkileyerek insülin üretimini ve salınımını da değiştirebilirler ve aynı zamanda immünotoksik etki göstermektedirler. $\mathrm{Bu}$ nedenle yapılan sınırlı sayıda epidemiyolojik çalışma ve hayvan çalışmaları tip 1 ve tip 2 diyabet gelişiminde bisfenol A (BPA), fitalatlar, yanmaz malzemeler, arsenik, dirençli organik kirleticiler ve pestisitler gibi endokrin bozucuların etkili olduğunu bildirmektedir (Sheau-Feng, Lin, Laybutt, Barres, Owens ve Morris, 2010; Alonso-Magdalena, Quesada ve Nadal, 2011).

Endokrin bozucular insanlarda vücut ağırlığı artışına ve insülin duyarlılığına neden oldukları ve endokrin sistemi etkiledikleri için metabolik bozucular olarak da adlandırılmaktadır (Casals-Casas ve Desvergne, 2011). Endokrin bozucuların metabolik etkileri ilk olarak Amerika Birleşik Devletleri'nde yapılan kesitsel bir çalışma ile diyabetli bireylerin, kardiyovaskuler hastalığı ve karaciğer fonksiyon bozukluğu olan bireylerin idrarlarında yüksek bisfenol A düzeylerinin belirlenmesi ile çalışılmaya başlanmıştır (Lang, Galloway, Scarlett, Henley, Depledge, Wallace ve diğ., 2008).

Yetişkin hastalıkların gelişimsel programlanması sonucu metabolik sendrom oluşumu ve bu süreçte maternal diyetin rolü bilinmektedir (Sheau-Feng ve diğ., 2010). Endokrin bozuculara maruziyetin gelişimsel programlamayı etkilediği bilinmesine karşın, doğrudan metabolik sendrom ile ilişkisi aydınlatılamamıştır. Ancak endokrin bozuculara maruziyetin metabolik sendromun öncüsü olan tip 2 diyabet ve obezite oluşumunda etkili olduğu bu nedenle metabolik sendrom oluşumunda da olası etkilerinin bulunduğu düşünülmektedir (Tang-Peronard, Andersen, Jensen ve Heitmann, 2011). İnsanlarda yapılan çalışmalarda da BPA maruziyetinin adipoz dokudan adiponektin salınımını inhibe ederek metabolik sendrom oluşumuna yol açabileceği belirtilmiştir (Hugo, Brandebourg, Woo, Loftus, Alexander ve Ben-Jonathan, 2008). 
Az sayıda çalışma bulunmakla birlikte; insanlarda kan glukoz homeostazını etkileyerek metabolik hastalıkların oluşumunda rol alabildiği düşünülen diğer endokrin bozucular arasında dioksinler (Bertazzi, Consonni, Bachetti, Rubagotti, Baccarelli, Zocchetti ve diğ., 2001; Henriksen, Ketchum, Michalek ve Swaby, 1997) ve arsenik de (Lai, Hsueh, Chen, Shyu, Chen, Kuo ve diğ., 1994; Meliker, Wahl, Cameron ve Nriagu, 2007) bulunmaktadır.

\section{Beslenme ve Endokrin Bozucular}

Beslenme ve endokrin bozucuların üç temel yol ile etkileşimi bildirilmiştir. Bunlar (Kordas, Lonnerdal ve Stoltzfus, 2007):

1. Endokrin bozucular besinler ile insan vücuduna alınabilmektedir: Endokrin bozucular ürün yetişirken ürüne geçebileceği gibi, depolama ve işleme yöntemleri ile de besini kontamine edebilirler (Finkelman, Belkin ve Zheng, 1999). Besinlerin endokrin bozucuların kaynağı olmasına en iyi örneklerden biri balık ve diğer deniz ürünlerinde belirlenen inorganik civa olabilir (Booth ve Zeller, 2005). İnorganik civa önce su kaynaklarını kontamine ederek, daha sonra bu su kaynaklarını kullanan canlıların yağ dokusunda birikmektedir. Bu balık ve deniz ürünlerinin tüketimi ile de besin zincirine katılarak, insanların yăg dokularında birikmektedir (Clarkson, Magos ve Myers, 2003).

2. Beslenme durumu çevresel endokrin bozuculara maruz kalma düzeyini ve maruziyetin sonuçlarını etkileyebilir: Bireylerin lipid profili, oksidatif stres düzeyi ve antioksidan düzeyleri gibi birçok faktör beslenme durumundan etkilenir. Bu parametrelerin hücre düzeyindeki değişimleri biyolojik işlevleri olumsuz yönde etkiler. Sonuç olarak endokrin bozucular hastalık ve işlevsel bozuklukların ortaya çıkmasına neden olur (Kordas ve diğ., 2007). Bu duruma en iyi örneklerden biri normalde zararlı olmadığ1 düşünülen dozlarda kurşun maruziyetinin beslenme durumu iyi olmayan çocuklarda zararlı etkilerinin gözlenmesidir (Lanphear, Hornung, Khoury, Yolton, Baghurst, Bellinger ve diğ., 2005).

3. Endokrin bozucu maddeler besin ögeleri ve besin ögelerinin metabolizması ile etkileşir: arsenik maruziyeti ile beslenme arasındaki ilişki bu duruma örnek olabilir. Arsenik maruziyeti oksidatif stres yaratarak vücudun antioksidan mekanizmalarını inhibe eder. Antioksidan desteği (askorbik asit, alfa tokoferol, flavanoidler ve selenyum alımı gibi) arseniğe bağlı toksisiteyi azaltabilir (Brown ve Ross, 2002; Rosado, Ronquillo, Kordas, Rojas, Alatorre, Lopez ve diğ., 2007). 
Beslenme ve endokrin bozucular ile ilgili bu etkileşim modellemesinde yaş ve cinsiyet gibi birçok etmen de göz önünde bulundurulmalıdır. Çünkü bu etmenler hem bireyin beslenme durumunu hem de endokrin bozuculara maruziyeti ve endokrin bozucuların etkilerini değiştirerek her iki süreci de etkileyebilirler (Kordas ve diğ., 2007).

\section{Sonuç ve Öneriler}

Nüfusun artışı ile artan gereksinimleri karşılamak için sanayinin gelişimine bağlı olarak son yıllarda kullanılan kimyasal sentetiklerin ve endokrin bozucu bileşenlerin doğaya yayılımı 400 milyon tona ulaşmıştır. Bunun sonucu olarak bilinen ve bilinmeyen etki mekanizmaları ile endokrin bozucular, endokrin sistemimize etki etmektedirler.

Endokrin bozucuların sağlığı bozucu etkileri olduğu yapılan birçok çalışma ile belirlenmiştir. Birçok endokrin bozucu, yağ dokusunda depolanabildiğinden vücudumuzda birikme özelliğine sahiptir. Günümüzde endokrin bozucu ajanlardan tümüyle korunmak olanaksızdır. Bu nedenle endokrin bozucuların sağlı̆̆ımız üzerindeki etkilerini en aza indirmek için yaşam tarzı değişiklikleri önem kazanmaktadır.

Endokrin bozucuların etkilerinden korunabilmek için yeterli ve dengeli beslenme alışkanlıkları geliştirilmelidir. Örneğin antioksidan vitaminlerin diyetle yeterli alımı arseniğin oksidatif stres oluşturmasına karşı koruyucu olabilir, düzenli fiziksel aktivite yapılması oksidatif, çevresel ve metabolik stresi azaltır. Yiyecek hazırlamada hijyen ve sanitasyona dikkat edilmesi besinler yolu ile endokrin bozuculara maruz kalınmasına karşı koruyucu olmaktadır. Meyve ve sebzeler kullanılan tarım ilaçlarından arındırmak için iyi yıkanarak tüketilmelidir. Kontaminasyonun yüksek olduğu bölgelerden elde edilen balıklar ve bu balıklarla beslenen yaban hayvanlarının etlerinin tüketiminden kaçınılmalıdır.

Çocukların beslenmesinde kullanılan plastik biberon ve besin hazırlama ve saklamada kullanılan araç ve gereçler BPA içerebilir. BPA bu malzemeler ile besine geçerek vücuda alınır. Besin saklamada kullanılan kapların besin ile etkileşime girmeyen bir malzemeden yapılmış olmasına (cam gibi) dikkat edilmelidir. Besinler kullanılan tarım ilaçları, depolama ve taşıma koşulları nedeniyle endokrin bozucular için taşıyıcı olabilirler. Bu nedenle üretimtüketim zincirinin her bir aşamasında izlenebilirliğin sürdürülmesinden sorumlu olan Gıda, Tarım ve Hayvancılık Bakanlığı'ndan üretim izni alınan besin ve besinle temas eden ambalaj malzemeleri satın alınmalıdır.

\section{Çıkar Çatışması}

Yazarlar ya da yazı ile ilgili bildirilen herhangi bir çıkar çatışması yoktur. 


\section{Kaynakça}

Alonso-Magdalena, P., Quesada, I., \& Nadal, A. (2011). Endocrine disruptors in the etiology of type 2 diabetes mellitus. Nat Rev Endocrinol, 7(6), 346-353. doi: 10.1038/nrendo.2011.56

Andreas Kortenkamp, O. M., Faust, M., Evans, R., McKinlay, R., Orton, F., \& Rosivatz, E. (2011). State Of The Art Assessment Of Endocrine Disrupters Final Report.

Anway, M. D., Cupp, A. S., Uzumcu, M., \& Skinner, M. K. (2005). Epigenetic transgenerational actions of endocrine disruptors and male fertility. Science, 308(5727), 1466-1469. doi: 10.1126/science.1108190

Anway, M. D., \& Skinner, M. K. (2008). Epigenetic programming of the germ line: effects of endocrine disruptors on the development of transgenerational disease. Reproductive BioMedicine Online, 16(1), 23-25. doi: http://dx.doi.org/10.1016/S14726483(10)60553-6

Barker, D. J. (2004). The developmental origins of adult disease. J Am Coll Nutr, 23(6 Suppl), 588S-595S.

Bertazzi, P. A., Consonni, D., Bachetti, S., Rubagotti, M., Baccarelli, A., Zocchetti, C. ve diğerleri. (2001). Health effects of dioxin exposure: a 20-year mortality study. Am J Epidemiol, 153(11), 1031-1044.

Boas, M., Feldt-Rasmussen, U., Skakkebaek, N. E., \& Main, K. M. (2006). Environmental chemicals and thyroid function. Eur $J$ Endocrinol, 154(5), 599-611. doi: 10.1530/eje.1.02128

Bolton, J. L., \& Thatcher, G. R. J. (2007). Potential Mechanisms of Estrogen Quinone Carcinogenesis. Chemical Research in Toxicology, 21(1), 93-101. doi: 10.1021/tx700191p

Booth, S., \& Zeller, D. (2005). Mercury, food webs, and marine mammals: implications of diet and climate change for human health. Environ Health Perspect, 113(5), 521-526.

Brown, K. G., \& Ross, G. L. (2002). Arsenic, Drinking Water, and Health: A Position Paper of the American Council on Science and Health. Regulatory Toxicology and Pharmacology, 36(2), 162-174. doi: http://dx.doi.org/10.1006/rtph.2002.1573

Casals-Casas, C., \& Desvergne, B. (2011). Endocrine disruptors: from endocrine to metabolic disruption. Апnи Rev Physiol, 73, 135-162. doi: 10.1146/annurev-physiol-012110142200

Caserta, D., Maranghi, L., Mantovani, A., Marci, R., Maranghi, F., \& Moscarini, M. (2008). Impact of endocrine disruptor chemicals in gynaecology. Hum Reprod Update, 14(1), 59-72. doi: 10.1093/humupd/dmm025 
Clarkson, T. W., Magos, L., \& Myers, G. J. (2003). The toxicology of mercury--current exposures and clinical manifestations. $N$ Engl J Med, 349(18), 1731-1737. doi: 10.1056/NEJMra022471

Çetinkaya, S. (2009). Endokrin Bozucular ve Ergenlik Üzerine Etkileri. Dicle Tıp Dergisi, 36(1), 59-66.

Diamanti-Kandarakis, E., Bourguignon, J. P., Giudice, L. C., Hauser, R., Prins, G. S., Soto, A. M. ve diğerleri. (2009). Endocrine-disrupting chemicals: an Endocrine Society scientific statement. Endocr Rev, 30(4), 293-342. doi: 10.1210/er.2009-0002

Diamanti-Kandarakis, E., Palioura, E., Kandarakis, S. A., \& Koutsilieris, M. (2010). The impact of endocrine disruptors on endocrine targets. Horm Metab Res, 42(8), 543-552. doi: $10.1055 / \mathrm{s}-0030-1252034$

Dirinck, E., Jorens, P. G., Covaci, A., Geens, T., Roosens, L., Neels, H. ve diğerleri. (2011). Obesity and persistent organic pollutants: possible obesogenic effect of organochlorine pesticides and polychlorinated biphenyls. Obesity (Silver Spring), 19(4), 709-714. doi: 10.1038/oby.2010.133

Eleni Palioura, Eleni Kandaraki, \& Diamanti-Kandarakis, E. (2011). Endocrine Disruptors and Endocrinopathies, Contemporary Aspects of Endocrinology. In D. E. DiamantiKandarakis (Ed.), Environmental Endocrinology: InTech. Retrieved from http://www.intechopen.com/books/contemporary-aspects-of endocrinology/ environmental-endocrinology-endocrine-disruptors-and-endocrinopathies

Finkelman, R. B., Belkin, H. E., \& Zheng, B. (1999). Health impacts of domestic coal use in China. Proc Natl Acad Sci U S A, 96(7), 3427-3431.

Gluckman P.D., Hanson M.A., (2004) Developmental origins of disease paradigm: a mechanistic and evolutionary perspective. Pediatr Res 56:311-317

Greenlee, A. R., Arbuckle, T. E., \& Chyou, P. H. (2003). Risk factors for female infertility in an agricultural region. Epidemiology, 14(4), 429-436.

Henriksen, G. L., Ketchum, N. S., Michalek, J. E., \& Swaby, J. A. (1997). Serum dioxin and diabetes mellitus in veterans of Operation Ranch Hand. Epidemiology, 8(3), 252-258.

Heyland, A., \& Moroz, L. L. (2005). Cross-kingdom hormonal signaling: an insight from thyroid hormone functions in marine larvae. J Exp Biol, 208(Pt 23), 4355-4361. doi: 10.1242/jeb.01877

Howdeshell, K. L. (2002). A model of the development of the brain as a construct of the thyroid system. Environ Health Perspect, 110 Suppl 3, 337-348.

Hugo, E. R., Brandebourg, T. D., Woo, J. G., Loftus, J., Alexander, J. W., \& Ben-Jonathan, N. (2008). Bisphenol A at environmentally relevant doses inhibits adiponectin release from human adipose tissue explants and adipocytes. Environ Health Perspect, 116(12), 1642-1647. doi: 10.1289/ehp.11537

Janesick, A., \& Blumberg, B. (2011). Endocrine disrupting chemicals and the developmental programming of adipogenesis and obesity. Birth Defects Res C Embryo Today, 93(1), 34-50. doi: 10.1002/bdrc.20197

Jenkins, S., Raghuraman, N., Eltoum, I., Carpenter, M., Russo, J., \& Lamartiniere, C. A. (2009). Oral exposure to bisphenol a increases dimethylbenzanthracene-induced 
mammary cancer in rats. Environ Health Perspect, 117(6), 910-915. doi: 10.1289/ehp.11751

Keith, L. H. (1998). Environmental Endocrine Disruptors. Pure and Applied Chemistry, 70(12), 2319-2326.

Keith, S. W., Redden, D. T., Katzmarzyk, P. T., Boggiano, M. M., Hanlon, E. C., Benca, R. M. ve diğerleri. (2006). Putative contributors to the secular increase in obesity: exploring the roads less traveled. Int J Obes (Lond), 30(11), 1585-1594. doi: 10.1038/sj.ijo.0803326

Kim, S., Park, J., Kim, H. J., Lee, J. J., Choi, G., Choi, S., ve diğerleri (2015). Association between several persistent organic pollutants and thyroid hormone levels in cord blood serum and bloodspot of the newborn infants of Korea. PloS One, 10(5), e0125213.

Kordas, K., Lonnerdal, B., \& Stoltzfus, R. J. (2007). Interactions between nutrition and environmental exposures: effects on health outcomes in women and children. $J$ Nutr, 137(12), 2794-2797.

Kortenkamp, A. (2007). Ten years of mixing cocktails: a review of combination effects of endocrine-disrupting chemicals. Environ Health Perspect, 115 Suppl 1, 98-105. doi: 10.1289/ehp.9357

Lai, M. S., Hsueh, Y. M., Chen, C. J., Shyu, M. P., Chen, S. Y., Kuo, T. L. ve diğerleri. (1994). Ingested inorganic arsenic and prevalence of diabetes mellitus. Am J Epidemiol, 139(5), 484-492.

Lang, I. A., Galloway, T. S., Scarlett, A., Henley, W. E., Depledge, M., Wallace, R. B., \& Melzer, D. (2008). Association of urinary bisphenol A concentration with medical disorders and laboratory abnormalities in adults. JAMA, 300(11), 1303-1310. doi: 10.1001/jama.300.11.1303

Lanphear, B. P., Hornung, R., Khoury, J., Yolton, K., Baghurst, P., Bellinger, D. C. ve diğerleri. (2005). Low-level environmental lead exposure and children's intellectual function: an international pooled analysis. Environ Health Perspect, 113(7), 894-899.

Mauvais-Jarvis, F., Clegg, D. J., \& Hevener, A. L. (2013). The Role of Estrogens in Control of Energy Balance and Glucose Homeostasis. Endocr Rev. doi: 10.1210/er.2012-1055

Meliker, J. R., Wahl, R. L., Cameron, L. L., \& Nriagu, J. O. (2007). Arsenic in drinking water and cerebrovascular disease, diabetes mellitus, and kidney disease in Michigan: a standardized mortality ratio analysis. Environ Health, 6, 4. doi: 10.1186/1476-069x-64

Moral, R., Wang, R., Russo, I. H., Mailo, D. A., Lamartiniere, C. A., \& Russo, J. (2007). The plasticizer butyl benzyl phthalate induces genomic changes in rat mammary gland after neonatal/prepubertal exposure. BMC Genomics, 8, 453. doi: 10.1186/1471-2164$8-453$

Morgan, M., Deoraj, A., Quentin, F., \& Roy, D. (2016). Environmental estrogen-like endocrine disrupting chemicals and breast cancer. Molecular and Cellular Endocrinology, pii: S0303-7207(16)30411-7. doi: 10.1016/j.mce.2016.10.003.

Newbold, R. R. (2010). Impact of environmental endocrine disrupting chemicals on the development of obesity. Hormones (Athens), 9(3), 206-217. 
Newbold, R. R., Padilla-Banks, E., Jefferson, W. N., \& Heindel, J. J. (2008). Effects of endocrine disruptors on obesity. Int J Androl, 31(2), 201-208. doi: 10.1111/j.13652605.2007.00858.x

Ng, S. F., Lin, R. C., Laybutt, D. R., Barres, R., Owens, J. A., \& Morris, M. J. (2010). Chronic high-fat diet in fathers programs beta-cell dysfunction in female rat offspring. Nature, 467(7318), 963-966. doi: 10.1038/nature09491

Rosado, J. L., Ronquillo, D., Kordas, K., Rojas, O., Alatorre, J., Lopez, P., \& Stoltzfus, R. J. (2007). Arsenic exposure and cognitive performance in Mexican schoolchildren. Environ Health Perspect, 115(9), 1371-1375. doi: 10.1289/ehp.9961

Sargis, R. M., Johnson, D. N., Choudhury, R. A., \& Brady, M. J. (2010). Environmental endocrine disruptors promote adipogenesis in the 3T3-L1 cell line through glucocorticoid receptor activation. Obesity (Silver Spring), 18(7), 1283-1288. doi: 10.1038/oby.2009.419

Sharpe, R. M., Skakkebaek E. N. (2003). Male reproductive disorders and the role of endocrine disruption: Advances in understanding and identification of areas for future research. ure and Applied Chemistry, 75(11-12), 2023-2038.

Skakkebaek, N. E., Rajpert-De Meyts, E., \& Main, K. M. (2001). Testicular dysgenesis syndrome: an increasingly common developmental disorder with environmental aspects. Hum Reprod, 16(5), 972-978.

Skinner, M. K. (2011). Environmental epigenomics and disease susceptibility. EMBO Rep, 12(7), 620-622. doi: 10.1038/embor.2011.125

Solecki, R., Kortenkamp, A., Bergman, Å., Chahoud, I., Degen, G. H., Dietrich, D. R. ve diğerleri. (2016). Scientific principles for the identification of endocrine disrupting chemicals - a consensus statement. In Outcome of an international expert meeting organized by the German Federal Institute for Risk Assessment (BfR). The statement is publicly available on the BfR webpage and has been submitted to the journal Environmental Health Perspectives for publication.

Tang-Peronard, J. L., Andersen, H. R., Jensen, T. K., \& Heitmann, B. L. (2011). Endocrinedisrupting chemicals and obesity development in humans: a review. Obes Rev, 12(8), 622-636. doi: 10.1111/j.1467-789X.2011.00871.x

Teilmann, G., Juul, A., Skakkebæk, N. E., \& Toppari, J. (2002). Putative effects of endocrine disrupters on pubertal development in the human. Best Practice \& Research Clinical Endocrinology \& Metabolism, 16(1), 105-121. doi: http://dx.doi.org/10.1053/beem.2002.0184

Tomei, G., Ciarrocca, M., Fortunato, B. R., Capozzella, A., Rosati, M. V., Cerratti, D., ve diğerleri (2006). Exposure to traffic pollutants and effects on 17- $\beta$-estradiol (E2) in female workers. International archives of occupational and environmental health, 80(1), 70-77.

vom Saal, F. S., Akingbemi, B. T., Belcher, S. M., Birnbaum, L. S., Crain, D. A., Eriksen, M. ve diğerleri. (2007). Chapel Hill bisphenol A expert panel consensus statement: integration of mechanisms, effects in animals and potential to impact human health at current levels of exposure. Reprod Toxicol, 24(2), 131-138. doi: 10.1016/j.reprotox.2007.07.005 
Walker, D. M., \& Gore, A. C. (2016). Epigenetic Impacts of Endocrine Disruptors in the Brain. Frontiers in Neuroendocrinology.

Woodruff, T. J., Carlson, A., Schwartz, J. M., \& Giudice, L. C. (2008). Proceedings of the Summit on Environmental Challenges to Reproductive Health and Fertility: executive summary. Fertil Steril, 89(2 Suppl), e1-e20. doi: 10.1016/j.fertnstert.2008.01.065

Zoeller, R. T. (2007). Environmental chemicals impacting the thyroid: targets and consequences. Thyroid, 17(9), 811-817. doi: 10.1089/thy.2007.0107 